\title{
Análise da efetividade da instrumentação associada à terapia fotodinâmica antimicrobiana e a medicação intracanal na eliminação de biofilmes de Enterococcus faecalis
}

\section{Analysis of the effectiveness of the instrumentation associated to antimicrobial photodynamic therapy and root canal dressing in the elimination of Enterococcus faecalis in root canals}

\section{Francine Cristina da SILVA}

Doutora em Biopatologia Bucal - Professora Adjunta de Microbiologia e Imunologia Geral - UFBA

- Vitória da Conquista - BA - Brasil.

\section{Lo Ruana Pereira de FREITAS}

Graduanda - Faculdade de Odontologia de São José dos Campos - UNESP - Univ Estadual Paulista - São José dos Campos - SP - Brasil.

\section{Ana Paula de Almeida LOURENÇO}

Cirurgiã-dentista - Faculdade de Odontologia de São José dos Campos - UNESP - Univ Estadual Paulista - São José dos Campos - SP - Brasil.

\section{Antonio Carlos Ricardo BRAGA JUNIOR}

Professora Assistente de Estatística e Matemática - UFBA - Vitória da Conquista - BA - Brasil.

\section{Antonio Olavo Cardoso JORGE}

Professor Titular de Microbiologia e Imunologia - Faculdade de Odontologia de São José dos Campos - UNESP - Univ Estadual Paulista - São José dos Campos - SP - Brasil.

\section{Luciane Dias de OLIVEIRA}

Professora Doutora de Microbiologia e Imunologia - Faculdade de Odontologia de São José dos Campos - UNESP - Univ Estadual Paulista - São José dos Campos - SP - Brasil.

\section{Cristiane Yumi KOGA-ITO}

Professora Adjunta de Microbiologia e Imunologia - Faculdade de Odontologia de São José dos Campos - UNESP - Univ Estadual Paulista - São José dos Campos - SP - Brasil.

\footnotetext{
Resumo

A eliminação total dos microrganismos dos canais radiculares é um procedimento de dificuldade extrema. O objetivo deste estudo foi avaliar in vitro a efetividade da instrumentação associada à Terapia Fotodinâmica (TFD) na eliminação de Enterococcus faecalis ATCC 29212 nos canais radiculares. Foram utilizadas 20 raízes dentárias humanas contaminadas com Enterococcus faecalis tendo 14 dias como período de incubação. Após esse tempo, foi realizada coleta do conteúdo intracanal que foi semeado em meio de cultura Tryptic Soy Agar. Das 20 raízes dentárias humanas, 10 foram utilizadas no grupo teste, em que os canais foram instrumentados e preenchidos com associação do corante azuleno 25\% e Endo-PTC (5g azuleno/15g Endo-PTC) durante 5 minutos e irradiados com laser ArGaAl por 3 minutos; as outras 10 raízes dentárias foram utilizadas no grupo controle, em que houve apenas a fase de instrumentação e não foi realizada a TFD. Outras duas coletas foram feitas, sendo uma imediatamente e outra após 7 dias da TFD, as quais receberam medicação intracanal (polimixina B com clorexidina gel 2\%) por 14 dias. A última coleta foi realizada depois de 7 dias da remoção da medicação. Os dados obtidos foram submetidos à análise estatística Mann-Whitney (5\%). Concluiu-se que a instrumentação associada à
} 
TFD frente a Enterococcus faecalis foi efetiva, mas não eliminou totalmente o biofilme intracanal monoespécie. Após o uso de medicação intracanal com clorexidina gel $2 \%$ associada à polimixina $\mathrm{B}$, não houve diferença no número de UFCs de Enterococcus faecalis entre o grupo tratado com TFD e aquele em que foi utilizada apenas a instrumentação.

\section{UNITERMOS}

Terapia fotodinâmica; laser; Enterococcus faecalis, endodontia.

\section{INTRODUÇÃO}

Os microrganismos podem alcançar os túbulos dentinários expostos através de lesões cariosas, superfícies dentárias desgastadas e trincas de esmalte relacionadas a traumas dentários. Dentre os acessos microbianos aos túbulos dentinários, pode-se incluir também exposição dos canais acessórios e do forame apical na doença periodontal, procedimentos restauradores, via hematogênica (anacorese) e exposição pulpar direta. Além destes, o comprometimento do selamento oclusal, as restaurações inadequadas de dentes previamente tratados, assim como a extensão periapical de uma lesão que se origina no dente adjacente infectado, podem ser vias de acesso ao sistema de canais radiculares [1].

Embora o favorecimento das espécies anaeróbias estritas seja fato consolidado na dinâmica da infecção endodôntica, estudos na literatura mencionam que bactérias anaeróbias facultativas são mais resistentes, inclusive à atividade dos antimicrobianos, do que os anaeróbios estritos, o que favorece a persistência dessas, mesmo após terapia endodôntica [1]. Os microrganismos anaeróbios facultativos, como os Enterococcus spp., podem permanecer em fase latente, com uma baixa taxa metabólica por um período de tempo;,entretanto, mudanças ambientais, como uma infiltração coronária, podem levar à ativação destes microrganismos e sua consequente proliferação [1]. Justamente pelas características e fatores de resistência que permitem o envolvimento de Enterococcus spp. com os casos mais complicados, é que estudos em Endodontia se preocupam em empregar a espécie na avaliação de seus métodos [2- 5].

A presença de Enterococcus faecalis influencia também o prognóstico do tratamento endodôntico, sendo sempre associada a prognósticos pouco favoráveis [4-6]. Os estudos evidenciam também a alta prevalência de isolados de Enterococcus faecalis em dentes comprometidos endodonticamente com lesões perirradiculares associadas, sugerindo um envolvimento desta na patogênese das lesões recorrentes [5,7].

Com vistas à eliminação de microrganismos no sistema de canal radicular, principalmente os re- sistentes como Enterococcus spp. é que a literatura sempre ressalta a importância das etapas de instrumentação, irrigação e medicação intracanal durante o tratamento endodôntico com vistas à eliminação da colonização microbiana do sistema de canais radiculares, principalmente pelo fato de os microrganismos serem apontados como os agentes etiológicos mais relacionados com o desenvolvimento de doenças pulpares e periapicais $[2,3,5,8]$.

$\mathrm{O}$ uso de medicação intracanal elimina microrganismos do sistema de canal radicular e tem sido relacionado com o aumento do sucesso na terapia endodôntica. As medicações intracanal são usadas com o intuito de eliminar microrganismos do sistema de canal radicular e prevenir proliferação microbiana entre as sessões do tratamento [9-13]. Também tem sido empregada com intuito de redução do processo inflamatório, minimização de algias e como auxiliar no processo de reparação dos tecidos acometidos $[1,10,12,14]$.

Algumas combinações da clorexidina com outras substâncias para uso como medicação intracanal têm sido observadas. Basrani et al.[15] corroboraram a afirmação de que a combinação da clorexidina gel $2 \%$ com hidróxido de cálcio pode ser utilizada como medicação intracanal. Evans et al.[16] avaliaram o efeito da mistura de hidróxido de cálcio com clorexidina $2 \%$ sobre Enterococcus faecalis em túbulos dentinários, demonstrando maior efetividade desta junção, se comparada ao hidróxido de cálcio associado à água destilada. Karin et al.[14] mencionaram a utilização de uma formulação de clorexidina clorada para utilização intracanal. Leonardo et al.[17] mencionaram a possibilidade da associação de substâncias capazes de inativar endotoxina como, por exemplo, a polimixina $\mathrm{B}$, na tentativa de eliminar seu potencial biologicamente tóxico. Como muitos produtos utilizados na inativação de endotoxinas possuem efeitos indesejáveis, a viabilidade destes quanto ao uso clínico deve ser investigada.

$\mathrm{Na}$ Endodontia, a utilização do laser de baixa potência associado a um corante com características fotossensibilizadoras, chamada Terapia Fotodinâmica ou FTD (PDT, Photodynamic Therapy), tem sido re- 
centemente explorada em diferentes estudos [6,18]. O interesse pela utilização da Terapia Fotodinâmica Antimicrobiana na Endodontia está relacionado principalmente ao efeito antimicrobiano comprovadamente constatado desta terapia, visto que ela não promove resistência microbiana, é uma técnica de fácil aplicação, é indolor, e soma a todas essas características os efeitos benéficos advindos da terapia com laser [6].

A capacidade da TFD na eliminação de microrganismos no interior de canais radiculares é promissora. Desta forma, o desempenho desses equipamentos com relação à segurança, à efetividade do comprimento de onda e dos níveis de energia e à redução microbiana deve ser bem documentado, a fim de viabilizar a utilização da TFD como coadjuvante ao tratamento endodôntico convencional.

Com base no exposto, o propósito deste estudo foi avaliar in vitro a eficácia da instrumentação associada à TFD com laser de baixa potência e corante azuleno, na eliminação de biofilmes intracanal monoespécies de Enterococcus faecalis. Foi também objetivo deste estudo analisar a efetividade da medicação intracanal de clorexidina gel $2 \%$, associada à polimixina $\mathrm{B}$, sobre Enterococcus faecalis remanescentes do tratamento com instrumentação e TFD.

\section{Material E Método}

O estudo foi aprovado pelo Comitê de Ética e Pesquisa Local, sob o protocolo no 060/2005-PH/CEP.

Foram utilizados 20 dentes humanos unirradiculares, divididos igualmente entre o grupo teste e controle; todos foram preparados pelo seccionamento das coroas dentárias padronizando-se o tamanho da raiz dentária em $16 \mathrm{~mm}$. Em seguida, foram instrumentados com limas tipo K (Dentsply Maillefer, Catanduva, São Paulo, Brasil), até diâmetro 30, com irrigação de 3 $\mathrm{ml}$ de solução fisiológica a cada troca de instrumento.

Foi realizado vedamento apical, com resina fotopolimerizável Z-100 (3M do Brasil, Sumaré, São Paulo, Brasil) e impermeabilização externa com duas camadas de adesivo epóxi ARALDITE (Brascola, Joinville, Santa Catarina, Brasil). Os dentes foram esterilizados e distribuídos aleatoriamente em duas placas de cultura celular de 24 poços com dez dentes em cada, fixados com resina acrílica quimicamente ativada e enviados à Empresa Brasileira de Radiação (EMBRARAD, Cotia, São Paulo, Brasil), para radiação gama com cobalto 60 (20 KGy.), para esterilização e neutralização de possíveis endotoxinas pré-existentes no interior dos canais radiculares.

Para a verificação da efetividade da TFD com laser de $\mathrm{ArGaAl}$, os canais radiculares foram contaminados com $10 \mu 1$ de suspensão padronizada por espectrofotometria de Enterococcus faecalis ATCC 29212, acrescida de $10 \mu 1$ de caldo triptic soy . Após a inoculação, os espécimes foram incubados a $37{ }^{\circ} \mathrm{C}$ durante 14 dias sendo que, a cada três dias, adicionou-se $20 \mu 1$ de meio de cultura ao canal radicular para a manutenção das condições nutricionais do ambiente. Após, foram realizadas coletas do conteúdo do canal confirmandose sua contaminação. Este conteúdo foi transferido para tubo de polipropileno tipo Eppendorf contendo $900 \mu \mathrm{L}$ de soro fisiológico estéril ou apirogênico. A seguir, foram realizadas diluições decimais de 10-2, 10-3 e 10-4 e alíquotas de $100 \mu 1$ foram semeadas em duplicata em placas contendo Tryptic Soy agar.

As placas foram incubadas a $37 \pm 1{ }^{\circ} \mathrm{C}$ por 48 horas, para verificação do crescimento microbiano e obtenção de unidades formadores de colônia (UFC/ ml) (coleta 1). Após a coleta do conteúdo do canal radicular, os espécimes foram incubados novamente a $37 \pm 1{ }^{\circ} \mathrm{C}$ por 24 horas. Confirmada a contaminação, os espécimes foram instrumentados até a lima tipo $\mathrm{K}$ $\mathrm{n}^{\circ} 50$ e escalonados até a lima tipo $\mathrm{K} \mathrm{n}^{\circ} 80$, utilizandose irrigação com $3 \mathrm{ml}$ de soro fisiológico apirogênico. Em seguida, foi realizada a TFD nos canais radiculares do grupo teste, preenchendo-os com associação do corante azuleno a 25\% com Endo-PTC, na proporção de $5 \mathrm{~g}$ de azuleno para $15 \mathrm{~g}$ de Endo-PTC (Manipulário - Farmácia de Manipulação, Taubaté, São Paulo, Brasil), por um período de 5 minutos e irradiados com laser de baixa intensidade de ArGaAl (Twin Laser MM Óptics, São Carlos, São Paulo, Brasil), com comprimento de onda $685 \mathrm{~nm}$, por 3 minutos, utilizandose sistema de entrega por fibra óptica de diâmetro de $365 \mu \mathrm{m}$ (coleta 2). No grupo controle houve somente a instrumentação (coleta 2). Os procedimentos posteriores foram realizados tanto no grupo teste quanto no controle da mesma maneira: incubação de 7 dias após tratamento com TFD (grupo teste) e só instrumentação (grupo controle) que corresponde à coleta 3; em seguida houve a medicação intracanal com 280 $\mu 1$ de polimixina B associada a $1 \mathrm{~g}$ de clorexidina gel $2 \%$ e incubação de 14 dias correspondente à coleta 4; finalizando, realizou-se a remoção da medicação intracanal incubando-se os espécimes por 7 dias com posterior coleta do conteúdo do canal radicular (coleta 5). Durante os intervalos entre as coletas não foram realizados outros procedimentos tanto no grupo teste quanto no controle. Os resultados foram observados por meio da contagem de UFC/ml obtidas nas coletas do conteúdo intracanal. Os dados foram analisados pelo teste estatístico de Mann-Whitney (5\%). 


\section{Resultados}

Os resultados foram comparados entre as coletas realizadas nos grupos teste e controle. Na comparação dos resultados de Enterococcus faecalis entre as coletas 1 não foram observadas diferenças estatisticamente significantes $(\mathrm{p}=0,290)$. Isso demonstra que não houve diferença no número de $\mathrm{UFC} / \mathrm{ml}$ de Enterococcus faecalis entre as mesmas coletas realizadas no grupo controle, em que se utilizou somente o tratamento com instrumentação, e o grupo teste, no qual foi utilizado o tratamento com instrumentação associada à Terapia Fotodinâmica Antimicrobiana.

$\mathrm{Na}$ análise dos resultados obtidos na coleta 2 , pôde-se verificar diferença estatisticamente significante $(\mathrm{p}=0,000)$, sendo que a média de $\mathrm{UFC} / \mathrm{ml}$ da coleta 2 do grupo teste foi menor do que no grupo controle, significando que a redução imediata no tratamento com instrumentação associada à TFD foi significativamente melhor em relação ao tratamento utilizando-se somente a instrumentação.
$\mathrm{Na}$ análise das médias de UFC/ml obtidas nas coletas 3, foram observadas diferenças estatisticamente significantes $(\mathrm{p}=0,005)$, sendo que a média de UFC/ml da coleta 3 no grupo teste foi menor que a mesma coleta no grupo controle, demonstrando que o tratamento com instrumentação associada à TFD não impediu o aumento da média de UFC/ml de Enterococcus faecalis.

$\mathrm{Na}$ análise dos resultados comparando-se as coletas 4 e coletas 5 dos grupos controle e teste, não houve diferença significante estatisticamente $(\mathrm{p}=$ 0,909 e $\mathrm{p}=1,000$, respectivamente), denotando que após a utilização da medicação intracanal, a média de UFC/ml no grupo controle e teste alcançou valores semelhantes e estes também foram semelhantes mesmo após remoção da medicação intracanal.

A Figura 1 apresenta os resultados obtidos no teste estatístico de Mann-Whitney (5\%), comparando as médias dos valores de UFC/ml de Enterococcus faecalis entre as mesmas coletas nos grupos controle e teste.

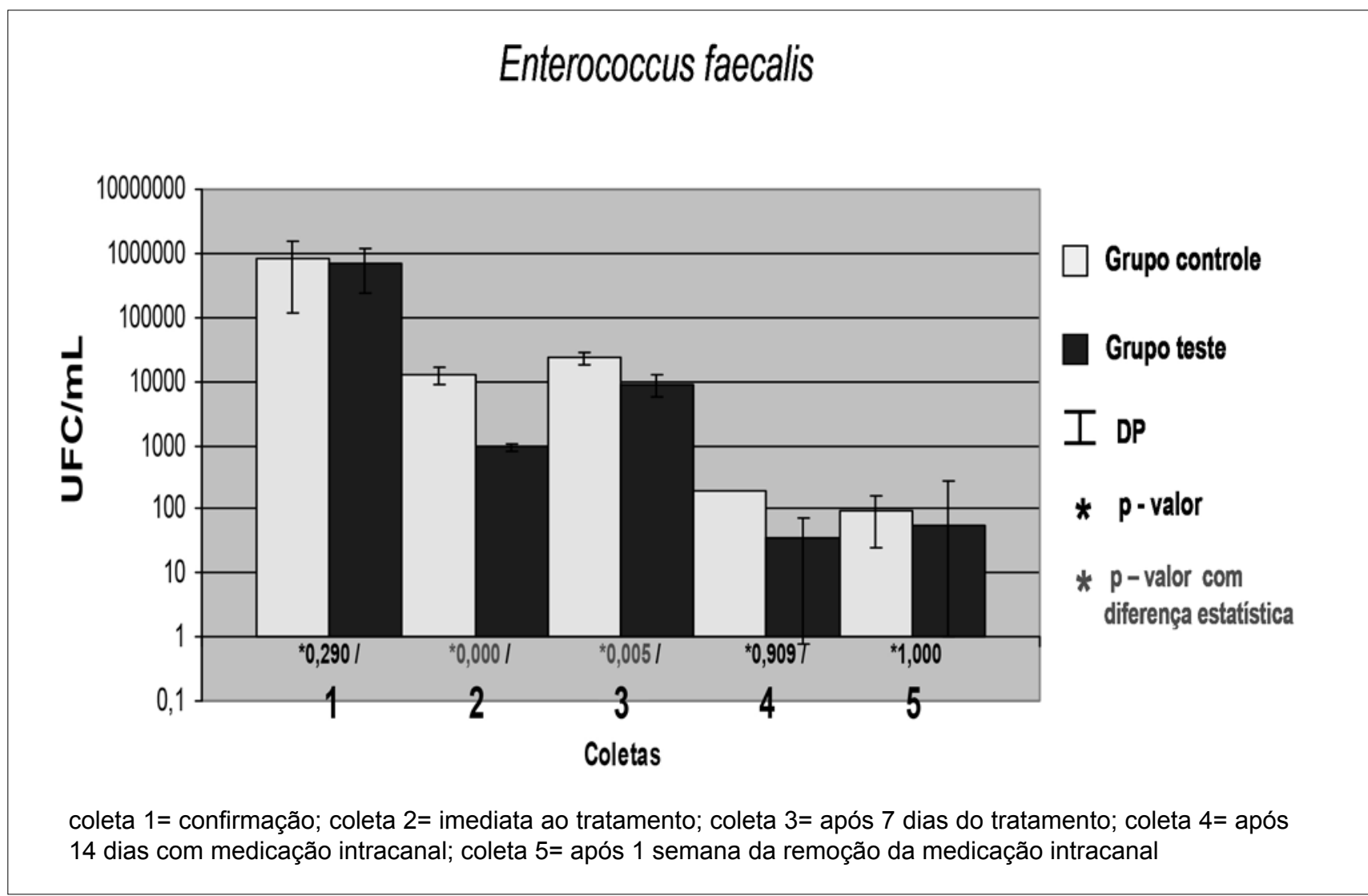

Figura1 - Gráfico demonstrando os resultados obtidos no teste estatístico de Mann-Whitney $(\alpha=5 \%)$, comparando as médias dos valores de UFC/ml nas mesmas coletas realizadas nos grupos controle e teste dos espécimes contaminados com Enterococcus faecalis. 


\section{Discussão}

As investigações sobre implantação da TFD como coadjuvante ao tratamento endodôntico, embora promissoras, necessitam do estabelecimento de protocolos viáveis para utilização efetiva, além de muitos estudos referentes às propriedades da técnica, aos efeitos biológicos sobre tecidos do hospedeiro e sobre os agentes infecciosos [2,6]. Este estudo buscou associar a TFD à instrumentação sem utilização de agentes químicos, a fim de contribuir cientificamente na admissão de um método terapêutico viável para introdução na clínica endodôntica, não desmerecendo etapas primordiais para promoção e manutenção das condições de desinfecção necessárias ao tratamento, como a etapa da instrumentação e medicação intracanal.

Neste estudo, o método de irradiação e o tipo de laser selecionados foram baseados nos protocolos definidos por Gutknecht et al. [19] e Segundo [20], por demonstrarem em seus estudos resultados relevantes sobre a efetividade da TFD com vistas ao tratamento endodôntico. A escolha pelo laser diodo a outros tipos de lasers está relacionada principalmente ao fato de ele ser recomendado para redução microbiana sem representar aumento na temperatura do tecido circundante, vantagem importante na aplicação da técnica para fins endodônticos[19]. Também foi levado em consideração o fato de as terapias utilizando lasers de baixa intensidade não favorecerem o desenvolvimento da resistência microbiana, pelo menos até onde se conhece atualmente [21,22].

Quanto à utilização do sistema de entrega por fibras ópticas, justifica-se pela compatibilidade com as dimensões dos canais radiculares permitindo que o feixe de irradiação alcance toda a extensão do canal radicular durante a ativação do corante fotossensibilizador. Foi utilizada neste estudo fibra óptica de diâmetro de $365 \mu \mathrm{m}$, com potência de saída do feixe de irradiação mensurada em $30 \mathrm{~mW}$, considerando perda de $10 \mathrm{~mW}$ de potência da saída do foco do aparelho. Moritz et al.[23] relataram que a confiabilidade da irradiação nos canais radiculares deve-se às fibras condutoras de luz flexíveis e de diâmetro compatível com o canal. Outros estudos, como de Kreisler et al. [24] e Garcez et al. [21], ressaltaram que, embora a fibra óptica possua dimensões importantes para a entrega do feixe às paredes internas dos canais radiculares, deve ser utilizada com muita cautela para que não haja rompimento da fibra no interior do canal, uma vez que a dificuldade na remoção dos fragmentos comprometeria o sucesso do tratamento.
No presente estudo, a associação do corante azuleno com o medicamento Endo-PTC teve por objetivo promover uma condição mais apropriada para uso clínico, melhorando as características da consistência do corante por torná-lo mais viscoso, facilitando assim a manipulação e introdução no interior dos canais radiculares. Esta associação também minimiza o potencial de manchamento dentário, evitando que o corante seja inadequado para utilização na clínica endodôntica [20].

Quanto aos procedimentos de inoculação dos espécimes no presente estudo, o tempo de formação do biofilme intracanal foi necessário para que houvesse penetração dos microrganismos nos túbulos dentinários e outras áreas do sistema de canal radicular, conferindo uma condição ambiental semelhante àquela que ocorre in vivo, possibilitando criar in vitro um desafio experimental que pudesse ser transposto clinicamente. Neste estudo foi utilizado o período de 14 dias de contaminação com a finalidade de promover uma condição de biofilme maduro no interior dos canais radiculares. Embora na literatura possam ser verificados períodos de contaminação dos espécimes distintos dos utilizados neste estudo [3, 21, 23], a determinação dos períodos está relacionada com os diferentes objetivos dos estudos que, nem sempre, necessitam de condição condizente com a situação clínica in vivo, como preconizada neste estudo.

A TFD com finalidade de fotossensibilização letal sobre microrganismos tem sido discutida sob vários aspectos na literatura mundial $[6,21,22,24]$. Os resultados promissores quanto à efetividade antimicrobiana foram atribuídos às vantagens inerentes à técnica para finalidade endodôntica, o que despertou o interesse pela investigação desta na Endodontia, já que a eliminação de microrganismos é um dos objetivos preponderantes do tratamento endodôntico $[21,6]$.

$\mathrm{Na}$ literatura foram relatadas diferenças na sensibilidade à TFD quando os microrganismos estão organizados sob a forma de biofilme e quando estão dispostos como células isoladas em um meio líquido, sendo que o desafio da TFD é maior quando os microrganismos estão organizados em forma de biofilmes [7]. No presente estudo foi possível observar que a TFD, no protocolo proposto frente a Enterococcus faecalis organizados na forma de biofilmes, teve certa dificuldade na eliminação da espécie, já que a redução alcançada no grupo de tratamento utilizando-se a TFD não foi de $100 \%$.

Nos resultados da análise da efetividade do protocolo de tratamento endodôntico associado à TFD frente a biofilmes intracanais monoespécie de Entero- 
coccus faecalis, foi possível observar que o padrão das fases do tratamento foi semelhante nos grupos controle e teste; entretanto, neste caso, a TFD apresentou uma redução no número de $\mathrm{UFC} / \mathrm{ml}$ de Enterococcus faecalis mais relevante do que a redução observada no grupo controle, em que foi utilizada somente a instrumentação. Além disso, os resultados deste estudo mostraram que, embora tenha ocorrido aumento no número de $\mathrm{UFC} / \mathrm{ml}$ de Enterococcus faecalis após sete dias do tratamento, no grupo teste este aumento permaneceu menor em relação ao observado no grupo controle. Estes resultados estão de acordo com os de Castro et al. [25], que utilizaram TFD com laser diodo (AsGaAl, $\lambda=685 \mathrm{~nm}$ e $\mathrm{P}=35 \mathrm{~mW}$ ) e corante fotossensibilizador azuleno associado ao Endo-PTC, e verificaram que a técnica foi capaz de reduzir o número de Enterococcus faecalis. Os resultados de Soukos et al.[6] também demonstraram que a TFD em canais radiculares, utilizando laser diodo com auxílio de fibra óptica $(\lambda=665 \mathrm{~nm}, \mathrm{P}=1 \mathrm{~W})$ e corante fotossensibilizador azul de metileno, foi capaz de reduzir a porcentagem de Enterococcus faecalis. Assim como nos resultados do presente estudo, Soukos et al.[6] verificaram que embora a TFD tenha reduzido a porcentagem de Enterococcus faecalis, não ocorreu erradicação total da espécie em canais radiculares. Em investigação realizada por Usacheva et al.[26] para analisar a sensibilidade dos microrganismos patogênicos à TFD, também foi verificada sensibilidade de Enterococcus faecalis independente do corante utilizado pelos autores (azul de metileno e azul de toluidina) com laser diodo ( $\lambda=664 \mathrm{~nm}, \mathrm{P}=50$ a $100 \mathrm{~mW})$. Neste caso, foi observado, ainda, que a TFD não foi capaz de eliminar completamente Enterococcus faecalis.

Foi possível observar também que ao final do ciclo experimental, após a utilização da medicação intracanal, a redução no número de UFC/ml de Enterococcus faecalis não apresentou diferença nos grupos controle e teste. Pôde-se verificar que a medicação contendo clorexidina mostrou desempenho muito importante, embora não tenha sido capaz de eliminar completamente a espécie organizada na forma de biofilme em canais radiculares. Estes resultados concordam com os encontrados por Gomes et al.[3], em que clorexidina gel utilizada como medicação intracanal inibiu o crescimento de Enterococcus faecalis, chegando a ser mais efetiva que hidróxido de cálcio, demonstrando também, assim como neste estudo, uma atividade residual por até 15 dias. Portenier et al.[4] verificaram eliminação de Enterococcus faecalis com clorexidina utilizada em diferentes concentrações e associada com outra medicação. Dametto et al.[2] fizeram observa- ções interessantes sobre a atividade antimicrobiana da clorexidina gel $2 \%$; sua utilização como irrigante tanto como medicação intracanal reduziu o número de UFC de Enterococcus faecalis e foi capaz de manter a condição alcançada por até 7 dias, comprovando a propriedade de substantividade da clorexidina, assim como observado no presente estudo, em que ao final do ciclo experimental houve a manutenção da condição de redução alcançada com o uso da medicação intracanal.

Segundo Gomes et al.[3], a atividade da clorexidina gel $2 \%$ depois de 15 dias sugere que a viscosidade na forma gel possibilita o contato do agente ativo com o canal e túbulos dentinários e que esta consistência é capaz de penetrar mais de $0,4 \mathrm{~mm}$ nos túbulos.

Dentre os resultados das investigações sobre a efetividade da TFD frente a Enterococcus faecalis analisada no presente estudo, não foram encontradas evidências sobre falta de atividade da TFD para a referida espécie. Este fato denota que é interessante o aprimoramento do protocolo de utilização da técnica em canais radiculares, uma vez que, mesmo em desafios na forma de biofilme e canais radiculares dotados de muitas anfractuosidades, a TFD tem atividade antimicrobiana sobre Enterococcus faecalis, uma das espécies mais resistentes ao tratamento endodôntico convencional.

Apesar de o presente estudo não ter incluído grupos experimentais analisando a efetividade da utilização do corante fotossensibilizador azuleno ou da irradiação laser de AsGaAl (no parâmetro da TFD) isoladamente, esses aspectos foram analisados em diferentes pesquisas, sob diferentes condições e, na grande maioria dos casos, não foram observados resultados relevantes na utilização isolada dessas condições. Os estudos comprovaram que essa forma de utilização não apresenta diferença com relação aos grupos designados como controle $[6,21,25]$.

É incontestável que, no tratamento endodôntico, as etapas de instrumentação, irrigação e medicação intracanal são essenciais para o sucesso do tratamento; entretanto, o melhoramento da técnica, dos medicamentos e materiais utilizados convencionalmente vêm ao encontro do objetivo de proporcionar sempre um tratamento de maior qualidade, menos dispendioso, mais confortável para o paciente e para o profissional e, principalmente, mais efetivo[3,8]. Todos esses fatores, sem dúvida, estão relacionados com a repercussão do sucesso do tratamento em Endodontia.

A TFD não deve ser desmerecida, nem exaltada pelos profissionais, segundo Müller et al.[27] Para tais autores, a aplicação da TFD não deve substituir os re- 
gimes dos tratamentos convencionais, mas precisa ser aprimorada no sentido de implementação como coadjuvante ao tratamento convencional, já que o laser de baixa intensidade é seguro, de fácil manipulação e aceitação pelo paciente, apresenta outras vantagens além de promover atividade antimicrobiana quando associado a um corante fotossensibilizador e é uma alternativa viável em relação ao custo relativamente baixo do aparelho emissor de irradiação.

Acreditamos que são necessárias investigações para aprimorar os resultados do protocolo de tratamento endodôntico proposto neste estudo, a fim de que sejam estabelecidos outros protocolos de tratamento passíveis de aplicação na clínica. Talvez, devido aos inúmeros fatores que influenciam na efetividade da TFD e à diversidade microbiana asso- ciada a cada quadro clínico endodôntico, os estudos encontrarão estratégias efetivas para cada condição específica, assim como já ocorre com os antibióticos atuais.

\section{Conclusões}

A partir dos resultados obtidos, concluiu-se que:

a) a instrumentação associada à TFD foi efetiva frente a Enterococcus faecalis, mas não eliminou totalmente o biofilme intracanal monoespécie;

b) após o uso de medicação intracanal com clorexidina gel $2 \%$ associada à polimixina $\mathrm{B}$, não houve diferença no número de UFCs de Enterococcus faecalis entre o grupo tratado com TFD e aquele em que foi utilizada apenas a instrumentação.

\begin{abstract}
The total elimination of microorganisms in root canals is an extremely difficult procedure. The aim of this study was to evaluate the in vitro efficacy of photodynamic therapy (PDT) associated to instrumentation for the elimination of Enterococcus faecalis ATCC 29212 in root canals. Twenty human dental roots were inoculated with E. faecalis. After 14 days of incubation, the results of intracanal content sampling were plated on tryptic soy agar. The canals were instrumented and filled with a mixture of $25 \%$ azulene and Endo-PTC for $5 \mathrm{~min}$, and the test group was irradiated with an ArGaAl laser for 3 min. Two more samplings that received intracanal medication (polymixin B with 2\% chlorhexidine gel) for 14 days were performed, one immediately and another 7 days after the photodynamic therapy. The last sampling was performed 7 days after removing the medication. The data were analyzed using the Mann-Whitney test. It could be concluded that the photodynamic therapy associated to instrumentation was effective against E. faecalis but did not totally eliminate the intracanal monospecies biofilm. After using the $2 \%$ chlorhexidine gel and polymixin B intracanal medication, no significant difference in the number of Enterococcus faecalis colony-forming unit (CFU) was observed between the group treated with PDT and the group treated with instrumentation only.
\end{abstract}

\title{
UNITERMS
}

Photodynamic therapy; laser; Enterococcus faecalis; endodontics.

\section{REFERÊNCIAS}

1. Belber VB. Verificação da redução de Enterococcus faecalis no canal radicular e nos túbulos dentinários utilizando diferentes substâncias químicas auxiliares e técnicas de instrumentação: estudo in vitro [dissertação]. Piracicaba: Faculdade de Odontologia de Piracicaba, Universidade Estadual de Campinas; 2005.

2. Dametto FR, Ferraz CCR, Gomes BPFA, Zaia AA, Teixeira FB, Souza-Filho FJ. In vitro assesment of the immediate and prolonged antimicrobial action of chlorhexidine gel as endodontic irrigant against Enterococcus faecalis. Oral Surg Oral Med Oral Pathol Oral Radiol Endod. 2005;99(6):768-2.

3. Gomes BPFA, Souza SFC, Ferraz CCR, Teixeira FB, Zaia AA, Valdrighi L, et al. Effectiveness of $2 \%$ chlorhexidine gel and calcium hydroxide against Enterococcus faecalis in bovine root dentine in vitro. Int Endod J. 2003;36(4):267-75.
4. Portenier I, Waltimo T, Ørstavik D, Haapasalo M. Killing of Enterococcus faecalis by MTAD and chlorhexidine digluconate with or without cetrimide in the presence or absence of dentine powder or BSA. J Endod. 2006;32(2):138-41.

5. Zoletti GO, Siqueira Jr JF, Santos KRN. Identification of Enterococcus faecalis in root-filled teeth with or without periradicular lesions by culture dependent and-independent approaches. J Endod. 2006;32(8):722-6.

6. Soukos NS, Chen PSY, Morris JT, Ruggiero K, Abernethy $\mathrm{AD}$, Som $\mathrm{S}$, et al. Photodynamic therapy for endodontic disinfection. J Endod. 2006;32(10):979-84.

7. Dunavant TR, Regan JD Glickman GN, Solomon ES, Honeyman AL. Comparative evaluation of endodontic irrigants against Enterococcus faecalis biofilms. J Endod. 2006;32(6):527-31.

8. Sakamoto M, Siqueira Junior JF, Rôças IN, Benno Y. Bacterial redution and persistence after endodontic treatment procedures. Oral Microbiol Immunol. 2007;22(1):19-23. 
9. Evanov C, Liewehr F, Buxton TB, Joyce AP. Antibacterial efficacy of calcium hydroxide and chlorhexidine gluconate irrigants at $37^{\circ} \mathrm{C}$ and $46^{\circ} \mathrm{C}$. J Endod. 2004;30(9):653-7.

10. Siqueira Junior JF, Rôças IN, Lopes HP, Magalhães FAC, Uzeda M. Elimination of Candida albicans infection of the radicular dentin by intracanal medications. J Endod. 2003;29(8):501-4.

11. Siqueira Junior JF, Paiva S, Rôças IN. Redution in the cultivable populations in infected root canals by a chlorhexidinebased antimicrobial protocol. J Endod. 2007;33(5):541-7.

12. Siqueira Junior JF, Rôças IN, Paiva SSM, Guimarães-Pinto T, Magalhães KM, Lima KC. Bacteriologic investigation of the effects of sodium hypochlorite and chlorhexidine during the endodontic treatment of teeth with apical periodontitis. Oral Surg Oral Med Oral Pathol Oral Radiol Endod 2007 July;104(1):122-30.

13. Wuerch RMW, Apicella MJ, Mines P, Yancich PJ, Pashley DH. Effect of $2 \%$ chlorhexidine gel as an intracanal medication on the apical seal of the root-canal system. J Endod. 2004;30(11):788-91.

14. Karim IE, Kennedy J, Hussey D. The antimicrobial effects of root canal irrigation and medication. Oral Surg Oral Med Oral Pathol Oral Radiol Endod 2007;103(4):560-9.

15. Basrani B, Ghanem A, Tja”derhane L. Physical and chemical properties of chlorhexidine and calcium hydroxide-containing medications.J Endod. 2004;30(6):413-7.

16. Evans MD, Baumgartner JC, Khemaleelakul S, Xia T. Efficacy of calcium hydroxide: chlorhexidine paste as an intracanal medication in bovine dentin. J Endod. 2003;29(5):338-9.

17. Leonardo MR, Silva RAB, Assed S, Nelson-Filho P. Importance of Bacterial endotoxin (LPS) in endodontics. J Appl Oral Sci. 2004;12(2):93-8.

18. Walsh, LJ. The current of laser applications in dentistry. Australian Dent J. 2003;48(3):146-55.

19. Gutknecht N, Franzen R, Vanweersch JML, Mir M. Temperature evolution on human teeth root surface after diode laser assisted endodontic treatment. Lasers Med Sci. 2005;20(2):99-103.

20. Segundo ASG. Laser em baixa intensidade associado à fotossensibilizador para redução bacteriana intracanal comparado ao controle químico [dissertação]. São Paulo: Universidade de São Paulo; 2002.

21. Garcez AS, Ribeiro MS, Tegos GP, Núñez SC, Jorge AOC, Hamblin MR. Antimicrobial photodynamic therapy combined with conventional endodontic treatment to eliminate root canal biofilm infection. Lasers Surg Med. 2007;39 (1):59-66

22. Haas R, Orhun D, Nikoletta MP, Georg M. Elimination of bacteria on different implant surfaces through photosensitization and soft laser: an in vitro study. Clin Oral Implants Res. 1997;8(4):249-54.

23. Moritz A, Gutknecht N, Goharkhay K, Schoop U, Wernisch $\mathrm{J}$, Sperr W. In vitro irradiation of infected root canals with a diode laser: results of microbiologic, infrared spectrometric, and stain penetration examinations. Quintessence Int. 1997;28(3):205-9.

24. Kreisler M, Kohnen W, Beck M, Haj HA, Christofers AB, Götz $\mathrm{H}$, et al. Efficacy of $\mathrm{NaOCl} / \mathrm{H} 2 \mathrm{O} 2$ irrigation and $\mathrm{GaA}$ 1As Laser in decontamination of root canals in vitro. Lasers Surg Med. 2003;32(3):189-96.

25. Castro MR, Brasil CO, Khouri S, Arisawa EAL. Avaliação in vitro do efeito da terapia fotodinâmica em suspensão de Enterococcus faecalis. Anais do X Encontro Latino America- no de Iniciação Científica e VI Encontro Latino Americano de Pós-Graduação da Universidade do Vale do Paraíba. São José dos Campos; 2006.

26. Usacheva MN, Teichert MC, Sievert CE, Biel MA. Effect of $\mathrm{Ca} 2+$ on the photobactericidal efficacy of methylene blue and toluidine blue against Gram-negative bacteria and the dye affinity for lipopolysaccharides. Lasers Surg Med. 2006;38(10):946-54.

27. Müller P, Guggenheim B, Schmidlin PR. Efficacy of gasiform ozone and photodynamic therapy on a multispecies oral biofilm in vitro. Eur J Oral. 2007;115(1):77-80.

Recebido: $10 / 05 / 2010$ Aceito: $13 / 01 / 2011$

Correspondência: Francine Cristina Silva Rosa Av. Olívia Flores, 3000 - Candeias Vitória da Conquista - BA CEP: 45055-090 e-mail: drfransilva@yahoo.com.br/franmicro@ufba.br 